\title{
Incidentally Detected Hepatocellular Carcinoma in Cirrhotic Children
}

\author{
Vidyut Bhatia • Swati Seth • Akshay Kapoor • \\ Anupam Sibal
}

Received: 15 May 2013 / Accepted: 15 July 2013 / Published online: 7 September 2013

(C) Dr. K C Chaudhuri Foundation 2013

To the Editor: Unlike hepatoblastoma, hepatocellular carcinoma (HCC) in children is rare and generally develops in the presence of some underlying liver disease and/or cirrhosis. In children it is usually associated with viral hepatitis, tyrosinemia, progressive familial intrahepatic cholestasis (PFIC) or rarely in biliary atresia [1]. Although, regular surveillance done by ultrasound examination and alpha-fetoprotein (AFP) testing leads to early detection of HCC, it can be missed and only detected incidentally during the histopathological analysis of explanted liver tissue [2-4].

We decided to look at the explanted liver histopathology of the last 35 children, without increased AFP or nodules on imaging, who had undergone a liver transplant at our center. The underlying etiology was biliary atresia $(n=16)$, PFIC $(n=8)$, Wilson disease $(n=4)$, cryptogenic cirrhosis $(n=6)$ and tyrosinemia $(n=1)$. All patients had been screened for biochemical markers like alpha-fetoprotein, viral markers (hepatitis B and C) and radiological imaging including ultrasonography and $\mathrm{CT}$ abdomen. The explanted livers were examined at intervals of $0.5 \mathrm{~cm}$. Two specimens $(5.7 \%)$ were detected to have an underlying HCC. Both the cases had single focus of the lesion. The diagnosis was PFIC in one case and cryptogenic cirrhosis in the other. Both the cases had no clinical features suggestive of HCC either during the surgery or on follow-up. The AFP levels were 6.7 and $8.5 \mathrm{mg} / \mathrm{dL}$ respectively. Both the children have remained well and have not shown any sign/symptom of HCC.

The rate of transition from established cirrhosis to HCC occurs at a rate of $1-4 \%$ per year [5]. The proportion of incidentally detected $\mathrm{HCC}$ in our series is $5.7 \%$ whereas in other studies it ranges from $9.74 \%$ to $63.3 \%$ [2-4]. Both our cases were unifocal whereas in reports from adults the incidence of multinodular HCC varies from 23.3 to $60 \%$. This could possibly be due to the lesser duration for which the liver remains cirrhotic in children. Incidental finding of hepatocellular carcinoma on explanted liver pathology is uncommon, but not rare [2-4]. Our study shows that biochemical and radiological screening may not always be helpful for detection of the malignant change in spite of extensive pre-transplant work up in cirrhotic children. Serum alpha-fetoprotein levels and ultrasound screening though helpful but are not absolute markers of the malignant change. If HCC is detected in explanted liver histopathology, the patient needs to be evaluated for the recurrence of HCC in follow-up.

\section{References}

1. Hadzic N, Quaglia A, Portmann B, Paramalingam S, Heaton ND, Rela M, et al. Hepatocellular carcinoma in biliary atresia: King's College Hospital experience. J Pediatr. 2011;159:617-22e1.

2. Choi SH, Lee HH, Lee DS, Choi JH, Heo JS, Lee KW, et al. Clinicopathological features of incidental hepatocellular carcinoma in liver transplantation. Transplant Proc. 2004;36:2293-4.

3. Raphe R, Felicio HC, Rocha MF, Duca WJ, Arroyo Jr PC, D'Santi Neto D, et al. Histopathologic characteristics of incidental hepatocellular carcinoma after liver transplantation. Transplant Proc. 2010;42:505-6.

4. Caroli-Bottino A, Nascimento CM, Basto S, Ribeiro J, Silveira V, Carvalho AM, et al. Hepatocellular carcinoma: Incidental finding in cirrhotic explanted livers. Transplant Proc. 2005;37:2791-2.

5. Di Bisceglie AM. Hepatitis C and hepatocellular carcinoma. Hepatology. 1997;26:34S-8.
V. Bhatia $(\bowtie) \cdot$ S. Seth $\cdot$ A. Kapoor $\cdot$ A. Sibal

Apollo Center for Advanced Pediatrics, Indraprastha Apollo

Hospital, New Delhi 110076, India

e-mail: drvidyut@gmail.com 